\title{
Latent Toxoplasmosis in Patients With Different Malignancy: A Hospital Based Study
}

\author{
Amal Nimir ${ }^{\mathrm{a}, \mathrm{c}}$, Amizah Othman ${ }^{\mathrm{b}}$, Soon Ee ${ }^{\mathrm{b}}$, Zohdy Musa ${ }^{\mathrm{b}}$, Iffah Abd Majid ${ }^{\mathrm{b}}$, Zalikha Kamarudin ${ }^{\mathrm{b}}$, \\ Chee Xian ${ }^{\mathrm{b}}$, Noor Hayati Isa ${ }^{\mathrm{b}}$
}

\begin{abstract}
Background: Seroprevalence of toxoplasmosis in different populations may vary according to different environments, social customs and habits. This study was designed to measure the seroprevalence of toxoplasmosis among patients with different malignancies and to ascertain the association between common risk factors and disease transmission.
\end{abstract}

Methods: This Cross-sectional study was from January to April of 2009. Four Oncology wards in Hospital Universiti Kebangsaan Malaysia (HUKM) were selected as the site for undertaking the present study. The survey involved 129 patients with different malignancies. Information was gathered by using study subject information sheet and a standardized structured questionnaire. Toxoplasma was screened by a standerd ELISA commercial kit in accordance with the manufacturer's instructions and performed at the Department of Microbiology, HUKM Kuala Lumpur. A result of $>51 \mathrm{IU} / \mathrm{ml}$ of anti-Toxoplasma (IgG) antibody was regarded as positive, indicating latent or pre-existing Toxoplasma infection. A result of $>51 \mathrm{IU} /$ $\mathrm{ml}$ of anti-Toxoplasma (IgM) antibody was regarded as positive, indicating recently acquired Toxoplasma infection.

Results: Total number of seropositive patients was $54(67.6 \%)$, the mean age was 51 years (range 15 - 88 years). Toxoplasma IgG positivity was highest among Malaysian (32\%). Male to female ratio was almost equal. There was a statistically significant difference in seropositivity between patients living in rural areas compared to those living in urban areas, positive history of consumption of undercooked meat and/or blood transfusion $(\mathrm{p}<0.05)$.

Manuscript accepted for publication May 26, 2010

${ }^{\mathrm{a}}$ Department of Pathology, Cyberjaya University College of Medical Sciences, Malaysia

${ }^{\mathrm{b}}$ Department of Parasitology, Universiti Kebangsaan Malaysia, Malaysia

cCorresponding author, Email: aralmadi@yahoo.com

doi:10.4021/jocmr2010.06.375w
Conclusions: These findings give some support to Toxoplasma screening program and health education, including promotion of a healthy lifestyle exclusively in seronegative patients in order to prevent seroconversion and the incidence of clinically evident opportunistic infection.

Keywords: Toxoplasma gondii; Risk factors; Immunocompromised; seroconversion; Seroprevalence

\section{Introduction}

Toxoplasma gondii (T. gondii) is a protozoan parasite that is endemic worldwide and is a major opportunistic pathogen in immunocompromised hosts. Infection is mainly acquired by ingestion of food, water or soil that is contaminated with oocysts shed by cats, or by eating undercooked or raw meat containing tissue cysts [1].

Primary infection is usually subclinical, but in severely immunocompromised patients it may be life-threatening. Most primary infections subsequently phase into chronic infections in which the parasite persist in tissue cysts, mainly in the brain, retina, skeletal and cardiac muscles [2]. These chronic infections probably persist indefinitely throughout the life and may remain undiagnosed until or unless it is reactivated as a result of severe immune suppression [3].

For the diagnosis of $\mathrm{T}$. gondii infection, detection of the organism itself is confirmative but very difficult. Thus, most clinical laboratories use serological tests to detect antibodies against $\mathrm{T}$. gondii such as the latex agglutination (LA) test, ELISA and indirect fluorescent antibody test because of its high specificity and sensitivity [4].

Seroprevalence in different populations may vary according to different environments, social customs and habits $[5,6]$. Analysis of worldwide reports indicated that about $38.5 \%$ humans, $32.9 \%$ cats and $24.2 \%$ goats were seropositive for toxoplasmosis [7].

This study was designed to measure the seroprevalence of toxoplasmosis among patients with different malignancies and to ascertain the association between common risk factors 
and disease transmission.

\section{Patients and Methods}

\section{Type of study and sampling}

This was a cross-sectional study from January to April of 2009. Random method was employed to select eligible patients.

\section{Study site and subjects}

Four Oncology wards in Hospital Universiti Kebangsaan Malaysia (HUKM) were selected as the site for undertaking the present study. The survey involved 129 patients with different malignancies.

\section{Demographic information}

Information was gathered by using study subject information sheet and a standardized structured questionnaire. An operational definition was used for risk factors. Contact with cats is defined as the one who is owner of one or more cats, or close contact with cats by straying, playing or feeding cats. Consumption of undercooked meat is defined as the one who has the habit of eating under-cooked meat where the method of preparation could not be guaranteed. Blood transfusion was defined as one who has received blood or blood products at least 3 months prior to the study period. Institutional permission was obtained before starting our study.

\section{Serologic studies}

Toxoplasma was screened by a standard ELISA commercial kit in accordance with the manufacturer's instructions and performed at the Microbiology Laboratory of HUKM. A re- sult of $>51 \mathrm{IU} / \mathrm{ml}$ of anti-Toxoplasma ( $\mathrm{IgG})$ antibody was regarded as positive, indicating latent or pre-existing Toxoplasma infection. A result of $>51 \mathrm{IU} / \mathrm{ml}$ of anti-Toxoplasma (IgM) antibody was regarded as positive, indicating recently acquired Toxoplasma infection.

\section{Statistical analyses}

Statistical analyses were conducted by using SPSS version 10.0 for Windows 2004. Chi-square test for significance at $95 \%$ confidence level and p value of less than 0.05 was considered statistically significant.

\section{Results}

During the three months of the study period, 129 samples of blood were collected from different patients. One blood sample $(0.77 \%)$ was positive for Toxoplasma IgM antibodies. Three patients $(2.32 \%)$ were positive for both $\operatorname{IgM}$ and $\mathrm{IgG}$, and fifty patients (38.75\%) had IgG positive blood samples. Leukaemic patients contribute the highest percentage of positive $\mathrm{IgG}$ results $(22 \%)$, followed by lymphoma $(14.4 \%)$, breast cancer $(7.3 \%)$, lung carcinoma $(3.5 \%)$ and other malignancies (4\%).

The mean age was 51 years (range15 - 88 years). The seroprevalence of toxoplasmosis was the highest in the age group of 20 - 41 years. Ethnic groups involved in this study were as follows: sixty nine Malay, fifty Chinese, four Indians and two Indonesian patients. Toxoplasma IgG positivity was highest among Malaysian (32\%), followed by Chinese $(17 \%)$, Indians $(1 \%)$ and $(0 \%)$ among the Indonesian patients. Male to female ratio was almost equal, (50.1\%) male and $(49.9 \%)$ female.

Table 1 shows some predisposing factors of toxoplasmosis, seropositivity rate of Toxoplasma antibody among patients living in rural areas was higher (41.3\%) compared

Table 1. Toxoplasma Seropositivity According To Residency and Occupation

\begin{tabular}{|c|c|c|c|c|}
\hline \multicolumn{4}{|l|}{ Group } & \multirow[t]{2}{*}{$P$ value } \\
\hline & Residency & & \\
\hline & Urban & \multicolumn{2}{|c|}{ Rural } & \\
\hline Seropositive & $21(26.6 \%)$ & \multicolumn{2}{|c|}{$33(41.3 \%)$} & 0.02 \\
\hline \multirow[t]{3}{*}{ Seronegative } & $54(67.5)$ & \multicolumn{2}{|c|}{$21(26.2 \%)$} & \\
\hline & Occupation & & & \\
\hline & Laborers & Non-laborers & others & \\
\hline Seropositive & $9(11.3 \%)$ & $29(36.3 \%)$ & $16(20.0 \%)$ & $>0.05$ \\
\hline Seronegative & $17(21.2 \%)$ & $21(26.3 \%)$ & $37(46.3 \%)$ & \\
\hline
\end{tabular}


Table 2. Relationship Between Toxoplasma Seropositivity and Some Risk Factors

\begin{tabular}{lrrr}
\hline Group & Seronegative & Seropositive & P value \\
\hline History of contact with cat & & & \\
Yes & $24(30.0 \%)$ & $24(30.0 \%)$ & $>0.05$ \\
No & $51(64.3 \%)$ & $30(37.5 \%)$ & $<0.05$ \\
Consumption of undercooked meat & & $<0.05$ \\
Yes & $21(26.3 \%)$ & $38(47.5 \%)$ & $<0.05$ \\
No & $36(45.0 \%)$ & $16(20.0 \%)$ & $<0.05$ \\
Blood transfusion & & & $<0.05$ \\
Yes & $54(67.5 \%)$ & $25(31.3 \%)$ & \\
No & $31(38.8 \%)$ & $19(23.8 \%)$ & \\
\hline
\end{tabular}

to patients living in urban areas $(26.6 \%)$. There was a statistically significant difference in seropositivity between the two groups of patients $(p<0.05)$. Among the seropositive patients, non-laborers represent a highest percentage compared to laborers and others. However, when multivariate analysis was performed, no significant association between Toxoplasma seroprevalence and the different occupational subgroups $(\mathrm{p}>0.05)$.

No statistically significant association between seropositivity and history of contact with cats $(\mathrm{p}>0.05)$. On the other hand, there is a significant association between seropositivity and positive history of consumption of undercooked meat and/or blood transfusion (Table 2).

\section{Discussion}

We found that seroprevalence of latent Toxoplasma among patients complaining of malignant diseases was $50(40 \%)$, which indicates that primary Toxoplasma infection appears to be subclinical and prevalent throughout life. This is a high rate when compared with previous studies in Malaysia [8, 9]. Studies in different parts of the world showed varying seroprevalence, for example, 7.7\% in United Kingdom [10], $13.6 \%$ in Thailand [11], 58.1\% in Egypt [12] and 67\% in Brazil [13]. The possible explanation for the differences could be due to the geographical variation of the precised study sites, different diagnostic methods employed in each study which have different sensitivities, and the possible risk factors contributing to the acquisition of Toxoplasma infection. It is suggested that any immunocompromised patient should request for testing of Toxoplasma infection, especially those who are at high risk to get infection or are IgM seropositive who requires close observation.

In this study, the seroprevalence of Toxoplasma IgM antibodies $4(5.0 \%)$ were positive. Of these, only one $(1.3 \%)$ suggested recent infection (only IgM antibody); an intermediate stage (IgG and $\operatorname{IgM}$ ) was found in $3(3.8 \%)$ patients. We followed-up each one of the patients' medical records throughout their time of hospital admission. No clinically active toxoplasmosis was identified among those patients. It may indicate that either subjects are asymptomatic, despite having a serological status indicating the recent infection, or the clinical signs and symptoms are not reliable in the diagnosis of toxoplasmosis in those patients. Therefore, we support proper guidelines for management of this silent disease to be enforced at any level of health provision, but particularly when dealing with immunocompromised patients in which this infection can be fatal.

Toxoplasmosis was considered to be acquired in early life and the prevalence increase with age and decline in later life [14]. From our study, toxoplasmosis was found to be higher in younger population compared to older age group, thus it was in agreement with the above mentioned studies.

From this study, the Malays showed higher significant association with Toxoplasma seroprevalence than their counterparts. These data suggest that the Malays are not only the major ethnic population in Malaysia but also that they are more likely to live a life style which makes them more liable to get this infection $[14,15]$.

Seropositivity rate of Toxoplasma antibody among patients living in rural areas was significantly higher $(p<0.05)$ 
than those who live in urban areas. Our results is in agreement with the study done in Kuala Lumpur which showed that the seropositivity of Toxoplasmosis is higher among patients staying outside the capital city than those who reside inside it [16].

The nature of occupations is known to pose a risk to infection by Toxoplasma gondii. Although non-laborers represent the highest percentage compared to laborers and other occupations, however, there was no statistical difference in seropositivity between the 3 groups of patients $(p>0.05)$. This can be due to the fact that non-laborers workers may not be directly involved in agricultural pursuits, but the confinement to the same environment where toxoplasmosis is being actively transmitted would have subjected them to the same risk factors [9].

\section{Acknowledgments}

We would like to express our gratitude to all those who gave us the chance to complete this research. We want to thank all the staffs of Oncology ward HUKM for giving us permission to commence this research. We have furthermore to thank the Department of Microbiology, HUKM especially Mr. Salehuddin Zainal.

\section{References}

1. Fayer R, Dubey JP, Lindsay DS. Zoonotic protozoa: from land to sea. Trends Parasitol 2004;20(11):531-536.

2. Darrel O Ho-Yen. Toxoplasmosis. Medicine 2005;33(5):120-121.

3. Pradhan S, Yadav R, Mishra VN. Toxoplasma meningoencephalitis in HIV-seronegative patients: clinical patterns, imaging features and treatment outcome. Trans R Soc Trop Med Hyg 2007;101(1):25-33.

4. Fan CK, Hung CC, Su KE, Sung FC, Chiou HY, Gil V, da Conceicao dos Reis Ferreira M, et al. Seroprevalence of Toxoplasma gondii infection among pre-schoolchildren aged 1-5 years in the Democratic Republic of Sao Tome and Principe, Western Africa. Trans R Soc Trop Med Hyg 2006;100(5):446-449.

5. Conrad PA, Miller MA, Kreuder C, James ER, Mazet J, Dabritz H, Jessup DA, et al. Transmission of Toxoplasma: clues from the study of sea otters as sentinels of Toxoplasma gondii flow into the marine environment. Int J Parasitol 2005;35(11-12):1155-1168.

6. Montoya JG, Liesenfeld O. Toxoplasmosis. Lancet 2004;363(9425):1965-1976.

7. Dubey JP, Su C, Cortes JA, Sundar N, Gomez-Marin JE, Polo LJ, Zambrano L, et al. Prevalence of Toxoplasma gondii in cats from Colombia, South America and ge- netic characterization of T. gondii isolates. Vet Parasitol 2006;141(1-2):42-47.

8. Ravichandran J, Rahmah Nkamaruzzaman A. Khairul Anwar A. Toxoplasma gondii antibodies among Malaysian pregnant women: a hospital based study. Biomedical research. 1998;1:25-28.

9. Nissapatorn V, Noor Azmi MA, Cho SM, Fong MY, Init I, Rohela M, Khairul Anuar A, et al. Toxoplasmosis: prevalence and risk factors. J Obstet Gynaecol 2003;23(6):618-624.

10. Allain JP, Palmer CR, Pearson G. Epidemiological study of latent and recent infection by Toxoplasma gondii in pregnant women from a regional population in the U.K. J Infect 1998;36(2):189-196.

11. Tantivanich S, Amarapal P, Suphadtanaphongs W, Siripanth C, Sawatmongkonkun W. Prevalence of congenital cytomegalovirus and Toxoplasma antibodies in Thailand. Southeast Asian J Trop Med Public Health 2001;32(3):466-469.

12. Hussein AH, Ali AE, Saleh MH, Nagaty IM, Rezk AY. Prevalence of toxoplasma infection in Qualyobia governorate, Egypt. J Egypt Soc Parasitol 2001;31(2):355363.

13. Reiche EM, Morimoto HK, Farias GN, Hisatsugu KR, Celler L, Gomes AC, Inoue HY, Rodrigues G, Matsue T. Prevalence of American trypanosomiasis, syphilis, toxoplasmosis, rubella, hepatitis B, hepatitis C, HIV, assayed through serologic tests among pregnant patients, from 1996 to 1998, at the regional university Hospital Norte do Parana. Revista da Sociedade Brasileira de Medicina tropical. 2000;33:519-527.

14. Thomas V, Sinniah B, Yap PL. Prevalence of antibodies including IgM to Toxoplasma gondii in Malaysians. Southeast Asian J Trop Med Public Health 1980;11(1):119-125.

15. Chan BTE, Amal RN, Noor Hayati MI et al. Comparative study of seroprevalence of toxoplasmosis between local workers and migrant workers in Malaysia. Archives of Medical Science. 2009;5(2):255-258.

16. Shamilah H, Lokman HS, Noor Azain MY. Seroprevalence of Toxoplasma gondii antibodies in HIV positive and negative patients using the immunofluorescence antibody test (IFAT) methods. Trop Biomed. 2001;18:137141.

17. Cook AJ, Gilbert RE, Buffolano W, Zufferey J, Petersen E, Jenum PA, Foulon W, et al. Sources of toxoplasma infection in pregnant women: European multicentre casecontrol study. European Research Network on Congenital Toxoplasmosis. Bmj 2000;321(7254):142-147.

18. Singh BA, Shashikant Singh S, Kapoor SK. Seroprevalence of Toxoplasma infection among primigravid women attending antenatal clinic at a secondary level hospital in North India. Journal of the Indian Medical Association. 2002;100:591-596. 